\title{
Safety Prediction of Deep Foundation Pit Based on Neural Network and Entropy Fuzzy Evaluation
}

\author{
Xie Xiudong ${ }^{1}$, Pan Caizhen ${ }^{1}$ \\ ${ }^{1}$ College of Civil Engineering of Fuzhou University, Fuzhou, Fujian, China
}

\begin{abstract}
The monitoring data can effectively reflect the safety status of the project during the construction of deep foundation pit, and the risks existing in the project can be discovered in time and the development trend can be reasonably predicted through the processing and analysis of the existing monitoring data. In this paper, a deep foundation pit in compound soil area of a coastal city was taken as an example, the BP neural network was taken to predict the monitoring data in the next stage, the entropy method was utilized to determine the weight of the evaluation index according to the predicted value, and the fuzzy comprehensive evaluation method was used to quantitatively describe the future safety status, so as to formulate targeted countermeasures and improve the construction safety.
\end{abstract}

\section{Introduction}

The subway is favored by major cities in China because of its advantages of saving land, low noise, efficient construction speed, and low pollution. Due to the large number of deep foundation pit engineering generated by subway construction, the construction safety issues have become the focus and difficulty in the current field of basic engineering. At present, the construction safety of deep foundation pits of subway stations in China is greatly affected by the subjective judgment of operators, which is reflected in the analysis of on-site monitoring data based on their own engineering experience. Before an engineering hazard develops into an engineering disaster, there are often abnormal reactions in monitoring data. If corresponding measures are taken, engineering risks can be reduced at a small $\operatorname{cost}^{[1]}$.

To improve the safety and precautions of deep foundation pit engineering, Yin Shengquan, and others combined on-site monitoring data with neural networks to give corresponding risk levels ${ }^{[2]}$. Wei Xinjiang et al. used the entropy method to determine the evaluation index weight and took into account the relationship between the index value and the rate of change ${ }^{[3]}$. Liu Junwei et al. established a foundation pit safety evaluation model based on the fuzzy evaluation theory and obtained the membership functions of deep foundation pits under different safety conditions ${ }^{[4]}$. Integrating the advantages of a neural network, entropy method, and fuzzy comprehensive evaluation method, this paper forecasts the evaluation indicators of the next phase based on the existing monitoring data, so as to predict the safety status of the foundation pit and quantitatively describe the risks in the project.

\section{BP Neural Network}

BP neural network is also called error backpropagation neural network. The weight adjustment adopts the backpropagation learning algorithm, which is a multilayer feedforward neural network composed of nonlinear transformation units, including an input layer, hidden layer, and output layer.

Foundation pit deformation is a nonlinear process with time-space effects, and it can use BP neural network technology with time domain. It exerts its powerful nonlinear mapping, evaluates indicators based on existing monitoring data, and builds a MATLAB-based BP neural network prediction model to predict the monitoring data within a short period.

\section{Entropy Method}

The entropy method is a utility value method developed on the basis of entropy theory, which reflects the information entropy value of each evaluation index. Foundation pit excavation is a complex and dynamic process. As the excavation progresses, the weight of each evaluation index in the safety evaluation of the foundation pit will continue to change. The entropy method is used to determine the evaluation index weight, which can fully consider the timeliness of the monitoring data. At present, this is more in line with the actual situation of foundation pit construction. When evaluating the safety status of the current foundation pit, if a certain index changes more widely in the current construction situation, the more weight is assigned to the evaluation index.

1) There are $m$ groups of monitoring data in chronological order during the excavation, and each group

Xie Xiudong:E-mail:zlxxd@163.com 
of monitoring data contains $n$ evaluation index. Use ${ }^{x_{i j}}$ to represent the measured value of the $j$ evaluation index in the monitoring data of the $i$ group.

2) The proportion of each measured value in the $j$ evaluation index:

$$
p_{i j}=\frac{x_{i j}}{\sum_{i=1}^{m} x_{i j}}
$$

3) Calculate the entropy value of each evaluation index:

$$
\mathrm{e}_{j}=-\frac{1}{\ln m} \sum_{i=1}^{m} p_{i j} \ln p_{i j}
$$

4) Calculate the weight of each evaluation index:

$$
w_{i}=\frac{g_{i}}{\sum_{i=1}^{n} g_{i}}=\frac{1-e_{i}}{n-\sum_{i=1}^{n} e_{i}}
$$

\section{Fuzzy Comprehensive Evaluation Theory}

A fuzzy comprehensive evaluation method is a method to comprehensively evaluate the evaluation object. It is based on fuzzy mathematics and replaces traditional logical thinking with dialectical thinking.

When evaluating the safety status of a foundation pit, all evaluation indexes must be considered comprehensively. In actual engineering, the evaluation indexes are interrelated but with vague evaluation standards. The fuzzy comprehensive evaluation method introduces the degree of membership and the membership function to quantitatively evaluate the safety status of the foundation pit. This contributes to describing the many influencing factors with precise mathematical language and clarifies the excessive amount of fuzzy information in the intermediary, which helps comprehensively evaluate the safety status of the foundation pit.

Assuming that $n$ evaluation indexes are used to evaluate the safety state of the foundation pit, the evaluation index set is $U=\left\{u_{1}, u_{2}, u_{3}, \ldots, u_{n}\right\}$.
Dividing the foundation pit engineering into four safety levels, the evaluation set is $V=\left\{v_{1}, v_{2}, v_{3}, v_{4}\right\}$, where $u_{i}$ represents the evaluation index and $v_{i}$ represents the safety level. According to the entropy method, the weight and the degree of membership of each index are obtained and expressed in vector form. The following mapping can be obtained through the membership matrix $R$ :

$$
U \stackrel{R}{\longrightarrow} V
$$

In the formula, three parameters of $U, V, R$ are the elements of the evaluation model.

\section{Engineering Case Analysis}

A subway station in a coastal compound land area is a two-line transfer station. The deep foundation pit has a total length of $220 \mathrm{~m}$, a width of $45 \mathrm{~m}$, and an excavation depth of about $19.8 \mathrm{~m}$. The supporting scheme adopted for the envelope structure is a $1000 \mathrm{~mm}$-thick diaphragm wall along with 3 concrete walls as supports. According to the existing 12 sets of historical monitoring data in the six evaluation index monitoring points around the QCX-12 monitoring point, this paper will predict the evaluation index in the next phase and prejudge the safety status of the foundation pit. A simplified schematic diagram of monitoring points is shown in Figure 1.

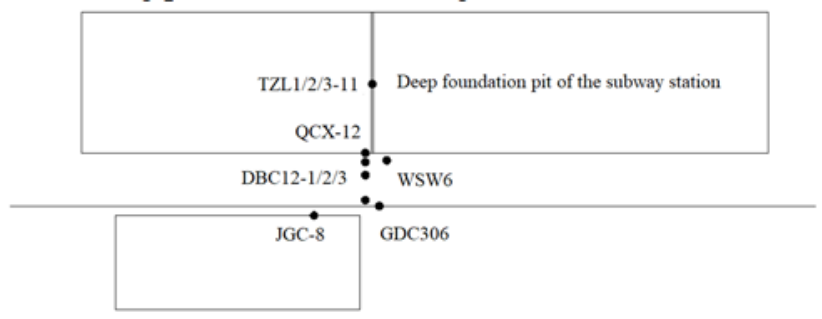

Figure 1 Schematic diagram of monitoring points

\subsection{Basic Flow of Foundation Pit Safety Prediction}

The specific flow of predicting the safety status of deep foundation pit construction based on monitoring data is shown in Figure 2. 


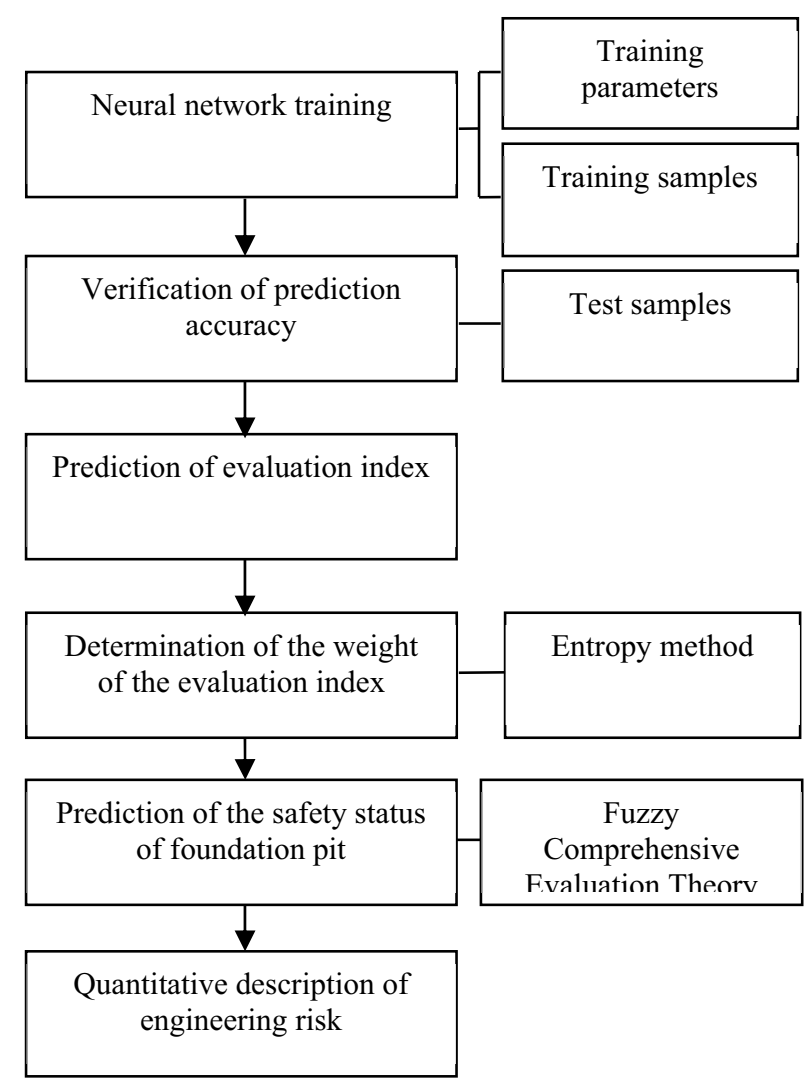

Figure 2 Flow chart of foundation pit safety prediction

\subsection{Dynamic prediction of evaluation indexes}

Chronologically, the first 9 groups of monitoring data were used as training samples, and the last 3 groups were used as test samples. Taking the first 4 groups in the training sample as input vectors and the next group as the target vector, the training samples were looped in turn. Then the trained network was used to predict the 10th group and the relative error was recorded. Afterward, the predicted value of the 10th group was replaced with the actual measured value to increase the number of original samples, and was retrained to predict the monitoring data of the 11th group, and so forth. As the excavation progressed, the number of training samples continued to increase, and the prediction under neural network training gradually became more reasonable. The training process is shown in Table 1.

Table 1 Schematic table of the training process

\begin{tabular}{cc}
\hline 4 input vectors & 1 target vector \\
\hline Monitoring data of & Monitoring data of the $5^{\text {th }}$ \\
the $1^{\text {st }}, 2^{\text {nd }}, 3^{\text {rd }}$, and $4^{\text {th }}$ & group \\
groups & \\
\hline
\end{tabular}

Monitoring data of the $2^{\text {nd }}, 3^{\text {rd }}, 4^{\text {th }}$, and $5^{\text {th }}$ groups

Monitoring data of the $3^{\text {rd }}, 4^{\text {th }}, 5^{\text {th }}$, and $6^{\text {th }}$ groups
Monitoring data of the $8^{\text {th }}, 9^{\text {th }}, 10^{\text {th }}$, and $11^{\text {th }}$ groups

The input vector of the network model contained 4 sets of monitoring data. There were 6 evaluation indexes in each group, so the number of neurons in the input layer was 24 . Since the output vector was 1 group of monitoring data, the number of neurons in each output layer was 6 . The neural network toolbox provided by MATLAB was adopted to write the BP neural network program. The training program was as follows:

1) $[\mathrm{P}, \min p, \operatorname{maxp}, T, \operatorname{mint}, \max \mathrm{t}]=\operatorname{premnmx}(\mathrm{p}, \mathrm{t})$

Define the training input sample $\mathrm{P}$ and the expected output sample $\mathrm{T}$, and normalize them;

2)net $=\operatorname{newff}(\operatorname{minmax}(\mathrm{P}),[5,6]$,

\{'tansig','purelin'\}, 'traingdx')

Call the newff function to create a BP neural network, with the number of neurons in the hidden layer and output layer set to 5 and 6 ;

3)net.trainParam.1r $=0.01$;

net.trainParam.epochs $=500$;

net.trainParam.goal $=0.001$;

net.trainParam. $\mathrm{mc}=0.9$;

net.trainParam. show $=50$;

Set training parameters;

4) $[$ net,tr] $=$ train(net,P,T);

$A=\operatorname{sim}($ net,p_test);

$\mathrm{A} 1=\operatorname{postmnmx}(\mathrm{A}, \operatorname{mint}, \operatorname{maxt})$;

Apply the training input sample $\mathrm{P}$ and the expected output sample $\mathrm{T}$ to train the neural network, and use the test input sample $p_{-}$test to get the predicted expected output sample A, and denormalize A. 
Table 2 Error analysis table

\begin{tabular}{|c|c|c|c|c|c|c|c|}
\hline Relativ & $\begin{array}{r}\text { Monitoring } \\
\text { Index }\end{array}$ & $\begin{array}{l}\text { Deep } \\
\text { horizontal } \\
\text { displacement } \\
\text { of walls } \\
(\mathrm{mm})\end{array}$ & $\begin{array}{l}\text { Brace force } \\
(\times 1000 \mathrm{KN})\end{array}$ & $\begin{array}{l}\text { Underground } \\
\text { water level } \\
\text { (m) }\end{array}$ & $\begin{array}{l}\text { Vertical } \\
\text { displacement } \\
\text { of } \\
\text { surrounding } \\
\text { surface } \\
(\mathrm{mm})\end{array}$ & $\begin{array}{l}\text { Vertical } \\
\text { displacement } \\
\text { of } \\
\text { surrounding } \\
\text { building } \\
\quad(\mathrm{mm})\end{array}$ & $\begin{array}{l}\text { Deformation } \\
\text { of } \\
\text { surrounding } \\
\text { pipeline }(\mathrm{mm})\end{array}$ \\
\hline \multirow{3}{*}{10} & $\begin{array}{l}\text { Predicted } \\
\text { value }\end{array}$ & 29.920 & 6.940 & -1.236 & -22.304 & -9.175 & -8.637 \\
\hline & $\begin{array}{l}\text { Measured } \\
\text { value }\end{array}$ & 28.9 & 6.865 & -1.26 & -23.2 & -9.1 & -8.4 \\
\hline & $\begin{array}{l}\text { Relative } \\
\text { error }\end{array}$ & $3.53 \%$ & $1.09 \%$ & $-1.94 \%$ & $-3.86 \%$ & $0.82 \%$ & $2.82 \%$ \\
\hline \multirow{3}{*}{11} & Predicted & 28.769 & 7.373 & -1.197 & -24.736 & -9.777 & -8.775 \\
\hline & $\begin{array}{l}\text { Measured } \\
\text { value }\end{array}$ & 30.2 & 7.086 & -1.24 & -24.8 & -9.5 & -8.6 \\
\hline & Relative & $-4.74 \%$ & $4.05 \%$ & $-3.46 \%$ & $-0.26 \%$ & $2.92 \%$ & $2.04 \%$ \\
\hline \multirow{3}{*}{12} & $\begin{array}{l}\text { Predicted } \\
\text { value }\end{array}$ & 34.302 & 7.166 & -1.328 & -28.182 & -9.723 & -9.062 \\
\hline & $\begin{array}{l}\text { Measured } \\
\text { value }\end{array}$ & 32.8 & 7.200 & -1.26 & -27.2 & -10.1 & -8.9 \\
\hline & $\begin{array}{c}\text { Relative } \\
\text { error }\end{array}$ & $4.58 \%$ & $-0.47 \%$ & $5.39 \%$ & $3.61 \%$ & $-3.73 \%$ & $1.82 \%$ \\
\hline
\end{tabular}

Note: Relative Error=(Predicted Value-Measured Value) / Measured Value

Table 3 Summary table of predicted values of evaluation indexes

\begin{tabular}{cllclll}
\hline & $\begin{array}{l}\text { Deep } \\
\text { horizontal } \\
\text { Major Evaluation } \\
\text { Index }\end{array}$ & $\begin{array}{l}\text { Brace force } \\
\text { of walls } \\
(\mathrm{mm})\end{array}$ & $\begin{array}{c}\text { Underground } \\
\text { water level } \\
(\times 1000 \mathrm{KN})\end{array}$ & $\begin{array}{l}\text { Vertical } \\
\text { displacement } \\
\text { of } \\
\text { surrounding } \\
\text { surface } \\
(\mathrm{mm})\end{array}$ & $\begin{array}{l}\text { Vertical } \\
\text { displacement } \\
\text { of } \\
\text { surrounding } \\
\text { building } \\
(\mathrm{mm})\end{array}$ & $\begin{array}{c}\text { Deformation } \\
\text { of } \\
\text { surrounding } \\
\text { pipeline }(\mathrm{mm})\end{array}$ \\
\hline Predicted Value & 35.5 & 7.236 & -1.26 & -30.0 & -10.5 & -9.1 \\
\hline
\end{tabular}

\subsection{Determination of evaluation index weight}

With the construction of the foundation pit progressing, the influence weight of each evaluation index in the safety evaluation of the foundation pit continued to change. The predicted value was listed as the 13 th group of monitoring data, as shown in Table 4.
According to formulas (1) (3) of the entropy method, 13 groups of monitoring data in Table 4 were calculated. The weight of each evaluation index for the next phase was obtained, as shown in Table 5.

Table 4 Summary Table of monitoring data

\begin{tabular}{|c|c|c|c|c|c|c|}
\hline $\begin{array}{l}\text { Monitoring } \\
\text { kndex } \\
\text { Time }\end{array}$ & $\begin{array}{c}\text { Deep } \\
\text { horizontal } \\
\text { displacement } \\
\text { of walls } \\
(\mathrm{mm})\end{array}$ & $\begin{array}{l}\text { Brace } \\
\text { force } \\
(\mathrm{KN})\end{array}$ & $\begin{array}{l}\text { Underground } \\
\text { water level } \\
\text { (m) }\end{array}$ & $\begin{array}{l}\text { Vertical } \\
\text { displacement } \\
\text { of } \\
\text { surrounding } \\
\text { surface } \\
(\mathrm{mm})\end{array}$ & $\begin{array}{l}\text { Vertical } \\
\text { displacement } \\
\text { of } \\
\text { surrounding } \\
\text { building } \\
\quad(\mathrm{mm})\end{array}$ & $\begin{array}{l}\text { Deformation } \\
\text { of } \\
\text { surrounding } \\
\text { pipeline }(\mathrm{mm})\end{array}$ \\
\hline 1 & 20.1 & 3945 & -1.10 & -15.1 & -5.6 & -4.9 \\
\hline 2 & 20.3 & 4267 & -1.20 & -15.5 & -5.9 & -5.1 \\
\hline 3 & 21.0 & 4677 & -1.19 & -16.3 & -6.6 & -5.5 \\
\hline 4 & 22.6 & 4980 & -1.16 & -16.5 & -6.8 & -5.9 \\
\hline 5 & 23.5 & 5177 & -0.99 & -17.2 & -7.2 & -6.5 \\
\hline 6 & 24.0 & 5280 & -1.00 & -17.5 & -7.6 & -6.9 \\
\hline 7 & 24.6 & 5588 & -1.11 & -19.2 & -7.9 & -7.2 \\
\hline
\end{tabular}




$\begin{array}{ccccccc}8 & 26.6 & 6050 & -1.14 & -20.1 & -8.1 & -7.7 \\ 9 & 27.5 & 6537 & -1.22 & -21.9 & -8.9 & -8.1 \\ 10 & 28.9 & 6865 & -1.26 & -23.2 & -9.1 & -8.4 \\ 11 & 30.2 & 7086 & -1.24 & -24.8 & -9.5 & -8.6 \\ 12 & 32.8 & 7200 & -1.26 & -27.2 & -10.1 & -8.9 \\ 13 & 35.5 & 7236 & -1.26 & -30.0 & -10.5 & -9.1\end{array}$

Note: The smaller the serial number, the earlier the time; the larger the serial number, the later the time.

Table 5 Summary table of index weights

\begin{tabular}{ccccccc}
\hline $\begin{array}{c}\text { Major evaluation } \\
\text { index }\end{array}$ & $\begin{array}{c}\text { Deep } \\
\text { horizontal } \\
\text { displacement } \\
\text { of walls }\end{array}$ & $\begin{array}{c}\text { Brace } \\
\text { force }\end{array}$ & $\begin{array}{c}\text { Underground } \\
\text { water level }\end{array}$ & $\begin{array}{l}\text { Vertical } \\
\text { displacement } \\
\text { of } \\
\text { surrounding } \\
\text { surface }\end{array}$ & $\begin{array}{l}\text { Vertical } \\
\text { displacement } \\
\text { of } \\
\text { surrounding } \\
\text { building }\end{array}$ & $\begin{array}{c}\text { Deformation } \\
\text { of } \\
\text { surrounding } \\
\text { pipeline }\end{array}$ \\
\hline $\begin{array}{c}\text { Entropy } e_{j} \\
\text { Coefficient of } \\
\text { difference } g_{i}\end{array}$ & 0.99388 & 0.99275 & 0.99884 & 0.99051 & 0.99311 & 0.99220 \\
Weight $w_{i}$ & 0.00612 & 0.00725 & 0.00116 & 0.00949 & 0.00689 & 0.00780 \\
\hline
\end{tabular}

\subsection{Prediction of the safety status of the foundation pit}

The fuzzy comprehensive evaluation method was applied to predict the safety status of the foundation pit for the next phase.

\subsubsection{Creation of weight set}

According to the influence weight of the six evaluation indexes for the next phase obtained by the entropy method, the weight set was:

$$
\begin{aligned}
A= & {[A 1, A 2, A 3, A 4, A 5, A 6] } \\
= & {[0.15799,0.18738,0.03006,} \\
& 0.24510,0.17809,0.20138]
\end{aligned}
$$

\subsubsection{Creation of factor set}

The factor set composed of the cumulative value of the six evaluation indexes was represented by $U_{l}$, and the factor set composed of the rate of change was represented by $U_{2}$ : $\mathrm{U}_{1}=\left\{\mathrm{u}_{11}, \mathrm{u}_{21}, \mathrm{u}_{31}, \mathrm{u}_{41}, \mathrm{u}_{54}, \mathrm{u}_{61}\right\}=\{$ Cumulative value of deep horizontal displacement of walls, pit Cumulative value of brace force, Cumulative value of underground water level, Cumulative value of vertical displacement of surrounding surface, Cumulative value of vertical displacement of surrounding building, Cumulative value of deformation of surrounding pipeline

$$
\mathrm{U}_{2}=\left\{\mathrm{u}_{12}, \mathrm{u}_{22}, \mathrm{u}_{32}, \mathrm{u}_{42}, \mathrm{u}_{52}, \mathrm{u}_{62}\right\}=\{\text { Change rate of }
$$
deep horizontal displacement of walls, Change rate of brace force, Change rate of underground water level, Change rate of vertical displacement of surrounding surface, Change rate of vertical displacement of surrounding building, Change rate of deformation of surrounding pipeline\}

Each factor in $U_{1}$ and $U_{2}$ was divided into four safety levels, including safety, attention, warning, and danger. The hierarchical control value of each factor was shown in Table 6.

Table 6 Summary table of factor control values

\begin{tabular}{clcccc}
\hline & Hierarchical control value & Safety & Attention & Warning & Danger \\
\cline { 3 - 6 } Factor & & $\begin{array}{c}70 \% \\
\text { warning }\end{array}$ & $\begin{array}{c}85 \% \\
\text { warning }\end{array}$ & $\begin{array}{c}100 \% \\
\text { warning level }\end{array}$ & $\begin{array}{c}110 \% \text { warning } \\
\text { level }\end{array}$ \\
\hline \multirow{2}{*}{$\begin{array}{c}\text { Deep horizontal } \\
\text { displacement of walls }\end{array}$} & Cumulative value $\mathrm{u}_{11}(\mathrm{~mm})$ & 21 & 25.5 & 30 & 33 \\
& Rate of change $\mathrm{u}_{12}(\mathrm{~mm} / \mathrm{d})$ & 2.1 & 2.55 & 3 & 3.3 \\
Brace force & Cumulative value $\mathrm{u}_{21}(\mathrm{KN})$ & 4831 & 5866 & 6902 & 7592 \\
& Rate of change $\mathrm{u}_{22}(\mathrm{KN} / \mathrm{d})$ & - & - & - & - \\
\multirow{3}{*}{ Underground water level } & Cumulative value $\mathrm{u}_{31}(\mathrm{~m})$ & 1.4 & 1.7 & 2 & 2.2 \\
& Rate of change $\mathrm{u}_{32}(\mathrm{~m} / \mathrm{d})$ & 0.35 & 0.425 & 0.5 & 0.55 \\
& Cumulative value $\mathrm{u}_{41}(\mathrm{~mm})$ & 21 & 25.5 & 30 & 33
\end{tabular}




\begin{tabular}{|c|c|c|c|c|c|}
\hline $\begin{array}{l}\text { Vertical displacement of } \\
\text { surrounding surface }\end{array}$ & Rate of change $u_{42}(\mathrm{~mm} / \mathrm{d})$ & 2.1 & 2.55 & 3 & 3.3 \\
\hline \multirow{2}{*}{$\begin{array}{l}\text { Vertical displacement of } \\
\text { surrounding building }\end{array}$} & Cumulative value $\mathrm{u}_{51}(\mathrm{~mm})$ & 14 & 17 & 20 & 22 \\
\hline & Rate of change $u_{52}(\mathrm{~mm} / \mathrm{d})$ & 1.4 & 1.7 & 2 & 2.2 \\
\hline \multirow{2}{*}{$\begin{array}{l}\text { Deformation of } \\
\text { surrounding pipeline }\end{array}$} & Cumulative value $\mathrm{u}_{61}(\mathrm{~mm})$ & 7 & 8.5 & 10 & 11 \\
\hline & Rate of change $u_{62}(\mathrm{~mm} / \mathrm{d})$ & 1.4 & 1.7 & 2 & 2.2 \\
\hline
\end{tabular}

\subsubsection{Creation of membership function}

The membership function of triangular distribution was selected as the membership function of each factor in $U_{I}$ and $U_{2}{ }^{[6]}$. Taking the cumulative value of the deep horizontal displacement of walls $U_{11}$ as an example, the expression of the membership function of the triangular distribution was briefly described here. It can be seen from Table 6 that the cumulative value $U_{11}$ of the deep horizontal displacement of walls was divided into the control values of four safety levels, which were $21 \mathrm{~mm}$, $25.5 \mathrm{~mm}, 30 \mathrm{~mm}$, and $33 \mathrm{~mm}$ respectively. The membership function curve was shown in Figure 3.

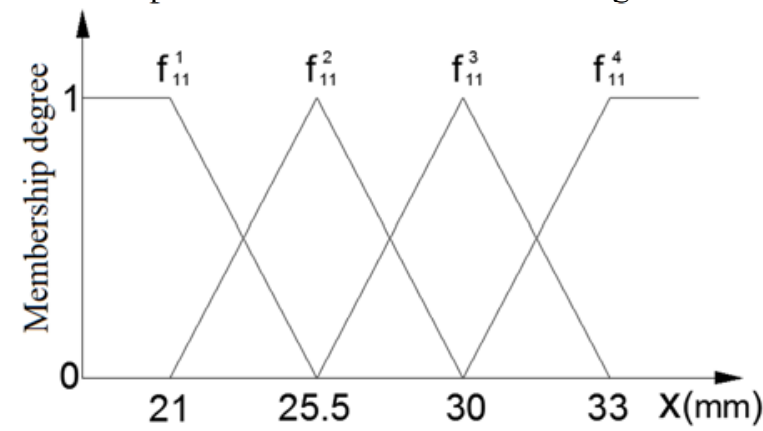

Figure 3 Membership function of the cumulative value of deep horizontal displacement of walls

The membership function expression of the cumulative value $U_{I I}$ of the deep horizontal displacement of walls was:

Safety: $f_{11}^{1}=\left\{\begin{array}{cl}1 & x \leq 21 \\ (25.5-x) / 4.5 & 21<x \leq 25.5 \\ 0 & x \leq 2 \text { lor } x>30\end{array}\right.$

Attention: $f_{11}^{2}=\left\{\begin{array}{cl}0 & x \leq 2 \text { lor } x>30 \\ (x-21) / 4.5 & 21<x \leq 25.5 \\ 0 & 25.5<x \leq 30\end{array}\right.$

Early-warning: $f_{11}^{3}=\left\{\begin{array}{cl}0 & x \leq 25.5 \text { or } x>33 \\ (x-25.5) / 4.5 & 25.5<x \leq 30 \\ (33-x) / 3 & 30<x \leq 33\end{array}\right.$

According to the predicted value of the deep horizontal displacement of walls, the corresponding membership degree of $U_{1 l}$ under the four safety levels was calculated:

$$
R_{11}=\left[\begin{array}{llll}
\mathrm{r}_{11}^{1} & \mathrm{r}_{11}^{2} & \mathrm{r}_{11}^{3} & \mathrm{r}_{11}^{4}
\end{array}\right]
$$

\subsubsection{Fuzzy comprehensive evaluation of a single index}

The predicted value was used to predict the safety status of the foundation pit for the next phase. The values of each factor in $U_{I}$ and $U_{2}$ were shown in Table 7.

Table 7 Summary table of factor values

\begin{tabular}{|c|c|c|c|c|c|c|c|c|c|c|c|c|}
\hline \multirow{2}{*}{ Value Factor } & \multicolumn{6}{|c|}{ Factor set of cumulative value $U_{l}$} & \multicolumn{6}{|c|}{ Factor set of change rate $U_{2}$} \\
\hline & $\mathrm{u}_{11}$ & $\mathrm{u}_{21}$ & $\mathrm{u}_{31}$ & $\mathrm{u}_{41}$ & $\mathrm{u}_{51}$ & $\mathrm{u}_{61}$ & $\mathrm{u}_{12}$ & $\mathrm{u}_{22}$ & $\mathrm{u}_{32}$ & $\mathrm{u}_{42}$ & $\mathrm{u}_{52}$ & $\mathrm{u}_{62}$ \\
\hline $\begin{array}{l}\text { Predicted } \\
\text { value }\end{array}$ & $\begin{array}{c}35 . \\
5\end{array}$ & 7236 & -1.26 & -30.0 & -10.5 & -9.1 & 2.7 & - & 0 & -2.8 & -0.4 & -0.2 \\
\hline Factor value & $\begin{array}{c}35 . \\
5\end{array}$ & 7236 & 1.26 & 30.0 & 10.5 & 9.1 & 2.7 & - & 0 & 2.8 & 0.4 & 0.2 \\
\hline
\end{tabular}

Liu Junwei ${ }^{[4]}$ and Zhang Jin ${ }^{[7]}$ found through research that, using the rate of change to prejudge the safety status of foundation pit construction was more accurate and timely than the cumulative value. Therefore, it was recommended that the weighted-average method be used to comprehensively consider the impact of these two combined. When calculating the membership degree of the evaluation index, if the rate of change factor was 4 times the cumulative value factor, it would be more in line with the factor importance evaluation standard, and also in line with engineering practice. According to the values of various factors in Table 7 and the corresponding membership functions, the membership degrees of the six evaluation indexes were calculated as:

Deep horizontal displacement of walls 


$$
\begin{aligned}
R_{11} & =\left(\begin{array}{ll}
0.2 & 0.8
\end{array}\right)\left(\begin{array}{l}
R_{11} \\
R_{12}
\end{array}\right) \\
& =\left(\begin{array}{llll}
0 & 0.5336 & 0.2664 & 0.2000
\end{array}\right)
\end{aligned}
$$

Brace force

$$
\begin{aligned}
R_{2} & =\left(\begin{array}{ll}
1 & 0
\end{array}\right)\left(\begin{array}{l}
R_{21} \\
R_{22}
\end{array}\right)=R_{21} \\
& =\left(\begin{array}{llll}
0 & 0 & 0.5160 & 0.4840
\end{array}\right)
\end{aligned}
$$

Underground water level

$$
\begin{aligned}
R_{3} & =\left(\begin{array}{ll}
0.2 & 0.8
\end{array}\right)\left(\begin{array}{l}
R_{31} \\
R_{32}
\end{array}\right) \\
& =\left(\begin{array}{llll}
1 & 0 & 0 & 0
\end{array}\right)
\end{aligned}
$$

Vertical displacement of surrounding surface

$$
\begin{aligned}
R_{4} & =\left(\begin{array}{ll}
0.2 & 0.8
\end{array}\right)\left(\begin{array}{l}
R_{41} \\
R_{42}
\end{array}\right) \\
& =\left(\begin{array}{llll}
0 & 0.3552 & 0.6448 & 0
\end{array}\right)
\end{aligned}
$$

Vertical displacement of surrounding building

$$
\begin{aligned}
R_{5} & =\left(\begin{array}{ll}
0.2 & 0.8
\end{array}\right)\left(\begin{array}{l}
R_{51} \\
R_{52}
\end{array}\right) \\
& =\left(\begin{array}{llll}
1 & 0 & 0 & 0
\end{array}\right)
\end{aligned}
$$

Deformation of surrounding pipeline

$$
\begin{aligned}
R_{6} & =\left(\begin{array}{ll}
0.2 & 0.8
\end{array}\right)\left(\begin{array}{l}
R_{61} \\
R_{62}
\end{array}\right) \\
& =\left(\begin{array}{llll}
0.8000 & 0.1200 & 0.0800 & 0
\end{array}\right)
\end{aligned}
$$

Taking the membership degrees of the six indicators into account, the membership matrix of the safety status of foundation pit construction for the next phase can be obtained:

$$
R=\left(\begin{array}{l}
R_{1} \\
R_{2} \\
R_{3} \\
R_{4} \\
R_{5} \\
R_{6}
\end{array}\right)=\left(\begin{array}{cccc}
0 & 0.5336 & 0.2664 & 0.2000 \\
0 & 0 & 0.5160 & 0.4840 \\
1 & 0 & 0 & 0 \\
0 & 0.3552 & 0.6448 & 0 \\
1 & 0 & 0 & 0 \\
0.8000 & 0.1200 & 0.0800 & 0
\end{array}\right)
$$

The membership degrees of foundation pit construction for the next phase were:

$$
\begin{aligned}
& B=A \cdot R=[B 1, B 2, B 3, B 4] \\
& =\left[\begin{array}{llll}
0.36926 、 & 0.19553 、 & 0.31292 、 & 0.12229
\end{array}\right]
\end{aligned}
$$

The membership degree for the next phase corresponding to the four safety levels of safety, attention, warning, and danger of the foundation pit construction was $0.36926,0.19553,0.31292$, and 0.12229 .

The basic scores corresponding to the four safety levels were:

\begin{tabular}{|c|c|c|c|}
\hline $\begin{array}{c}\text { Comprehensive } \\
\text { evaluation score } \mathrm{F}\end{array}$ & $\begin{array}{l}\text { Safety level of } \\
\text { foundation pit }\end{array}$ & Description & Response \\
\hline $80 \sim 100$ & Safety & $\begin{array}{l}\text { The foundation pit does not tend } \\
\text { to deform or damage, and the } \\
\text { foundation pit system is safe. }\end{array}$ & Normal construction \\
\hline $60 \sim 80$ & Attention & $\begin{array}{l}\text { The foundation pit has the } \\
\text { tendency and signs of } \\
\text { deformation and damage, but } \\
\text { relatively safe for now. }\end{array}$ & $\begin{array}{l}\text { It is necessary to attract the } \\
\text { attention of all parties involved } \\
\text { in the construction and analyze } \\
\text { the development trend of } \\
\text { deformation. }\end{array}$ \\
\hline $40 \sim 60$ & Warning & $\begin{array}{l}\text { The construction has certain } \\
\text { safety hazards and is prone to } \\
\text { danger in this state. }\end{array}$ & $\begin{array}{l}\text { The construction unit shall hold } \\
\text { a monitoring and warning } \\
\text { analysis meeting, and take } \\
\text { necessary emergency measures. }\end{array}$ \\
\hline 40 & Danger & $\begin{array}{l}\text { The safety risk is very high, and } \\
\text { construction should be } \\
\text { temporarily stopped. }\end{array}$ & $\begin{array}{l}\text { The construction unit shall } \\
\text { invite relevant experts to } \\
\text { participate in the rescue } \\
\text { meeting, and take relevant } \\
\text { rescue measures based on the } \\
\text { site conditions. }\end{array}$ \\
\hline
\end{tabular}

$$
T=\left\{T_{1}, T_{2}, T_{3}, T_{3}\right\}=\{100,80,60,40\}
$$

The comprehensive evaluation score of the safety status of the foundation pit construction for the next phase was:

$$
\mathrm{F}=\mathrm{B} \times T=0.36926 \times 100+0.19553 \times 80+0.31292
$$$$
\times 60+0.12229 \times 40=76.24
$$

It can be seen in Table 8 that the corresponding relationship between the comprehensive evaluation score and the safety level of the foundation pit construction was $80>76.24>60$, and the safety level of the next stage can be prejudged as attention. Therefore, the foundation pit system was relatively safe at that time and can be constructed normally.

Table 8 Correspondence between comprehensive evaluation score and safety level of foundation pit construction 


\subsection{Risk Prediction of Foundation Pit}

It can be seen from the membership matrix $R$ that, in the foundation pit for the next phase, the membership degrees of the deep horizontal displacement of walls $R_{I}$ and the brace force $R_{2}$ under the danger level are 0.2000 and 0.4840 respectively, and other indexes are all 0 . This indicates that the risks for the next phase are mainly the deformation of the enclosure structure and the excessive brace force of the concrete support. If it continues to develop, it may cause damage and endanger the safety of the foundation pit.

The prediction result helps all parties involved in the construction to formulate effective measures to control the deformation of the supporting structure in advance, so as to ensure the safety and stability of the foundation pit construction.

\section{Conclusion}

(1) The trained BP neural network prediction model can make a more accurate prediction of the evaluation index based on the monitoring data in a short time. Combined with the timeliness of the entropy method, it can obtain the influence weight of each evaluation index in the safety evaluation of the foundation pit for the next phase.

(2) Fuzzy comprehensive evaluation method introduces the concepts of membership degree and membership function, which better tackles with the ambiguity and relevance of safety risks in foundation pit excavation. Through the quantitative evaluation of the later construction safety status, the foundation pit engineering is divided into four safety levels, including safety, attention, warning, and danger, making the prediction results more realistic.
(3) The membership matrix quantitatively describes the construction risks for the next phase, contributing to control engineering risks and improving the function of safety predicting of foundation pits.

\section{References}

1. Liu Chaoming. Data Mining Achievement of Pit Excavations and Safty Analysis [J]. Urban Rail Transit, 2006, 9(12):57-60.

2. Yin Shengquan, Liang Fayun, Yao Xiaoqing. Dynamic Risk Prediction for the Deep Excavations Based on Neutral Networks and It's Applications [J]. Chinese Journal of Underground Space and Engineering, 2011, 07(5):996-1000.

3. Wei Xinjiang, Ding Zhi. Safety Evaluation of Foundation Pits by Extension Assessment Method Combined with Entropy Law. Chinese Journal of Geotechnical Engineering, 2008 (s1): 672-676.

4. Liu Junwei, Shang Wenchang, Yu Xiuxia. Risk Assessment on Deep Excavation Construction Based on Fuzzy Evaluation Theory[J]. Chinese Journal of Underground Space and Engineering, 2016, 12(3):825-830.

5. Meng Fanli, Zheng Qi, Li Yan. Deformation predictionof deep foundation pit based on BP neural network[J]. Journal of Zhejiang University of Technology, 2014, 42(4):367-372.

6. Kou Runsheng. Settlement's Prediction and Safety Assessment of Building around Deep Foundation Pit[D]. Chongqing University, 2014.

7. Zhang Jin. Research of safety evaluation for deep excavating foundation based on the field measured data[D]. Tongji University, 2008. 